\title{
White Light-Activated Antimicrobial Surfaces ; Effect of Nanoparticles Type on Activity
}

Gi Byoung Hwang ${ }^{a}$, Sacha Noimark ${ }^{a}$, Kristopher Page ${ }^{a}$, Sandeep Sehmi ${ }^{a}$, Alexander J. Macrobert ${ }^{b}$, Elaine Allan ${ }^{c}$ and Ivan P. Parkin ${ }^{a *}$

${ }^{a}$ Materials Chemistry Research Centre, Department of Chemistry, University College London, 20 Gordon Street, London, WC1H OAJ, United Kingdom

${ }^{b}$ National Medical Laser Centre, UCL Division of Surgery and Interventional Science, Royal free campus, Rowland Hill street, London, NW3 2PF United Kingdom

${ }^{c}$ Division of Microbial Diseases, UCL Eastman Dental Institute, University College London, 256 Gray's Inn Road, London WC1X 8LD, United Kingdom

${ }^{*}$ To whom correspondence should be addressed.

E-mail: i.p.parkin@ucl.ac.uk Tel: 44(0)207 6794669 


\section{Abstract}

Toluidine blue O (TBO) dye together with either silver (Ag) nanoparticles (NPs), gold (Au) NPs, or a mixture of $\mathrm{Ag}$ and $\mathrm{Au}$ NPs (Mix $\mathrm{Ag}-\mathrm{Au} \mathrm{NPs}$ ) were incorporated into polyurethane to make antimicrobial surfaces using a swell-encapsulation-shrink process. Antimicrobial testing against Escherichia coli showed that inclusion of the NPs significantly enhanced the antimicrobial activities of the TBO polyurethane samples. In particular, samples containing Ag NPs exhibited potent antimicrobial activity under white light and surprisingly, also in the dark. The numbers of viable bacteria decreased below the detection limit on the TBO/Ag NPs incorporated samples within $3 \mathrm{~h}$ and $24 \mathrm{~h}$ under white light and dark conditions. A mechanistic study using fufuryl alcohol indicated that the enhanced photobactericidal activity was most likely due to a type I photochemical reaction. To the best of our knowledge, this is the first report of an antimicrobial surface comprised of a combination of Ag NPs and a light activated agent to provide a dual kill mechanism. These surfaces are promising candidates for use in healthcare environments to reduce the incidence of hospital-acquired infections.

Keywords: silver nanoparticles, gold nanoparticles, white light activated antimicrobial surface, toluidine blue O, E. coli bacteria 


\section{Introduction}

Healthcare-associated infections (HAIs) are infections acquired from the result of a person's treatment by health care providers. HAIs in hospitals are caused by a variety of micro-organisms and cause a range of symptoms from minor discomfort for patients to prolonged and permanent disability and even death in some cases. ${ }^{[1,2]}$ HAIs include gastrointestinal infections (22\%), urinary tract infections (20\%), low respiratory tract infections (20\%), surgical site infections (14\%), skin and soft tissue infections (10\%), bloodstream infections (7\%) and others (7\%). ${ }^{[3]}$ Annually, there are at least 300,000 incidents of HAIs in hospitalized patients in England, costing the UK's National Health Service $\left(\right.$ NHS) $>1$ billion pounds a year. ${ }^{[3,4]}$

In recent years, the NHS has implemented a range of strategies, including mandatory surveillance, legislation, and inspection in order to decrease the number of HAIs. In particular, significant effort has been devoted to prevent HAIs attributed to meticillin resistant Staphylococcus aureus (MRSA), and Clostridium difficile because they have caused multiple fatalities. ${ }^{[5,6]}$ Although the actions have achieved a reduction in HAIs since 2007, fatality rate ( 9000 deaths per year) is still tragically high and requires further control measures. ${ }^{[3]}$

Contaminated surfaces in hospitals serve as a bacterial reservoir which is able to contribute to transmission of health care-associated pathogens via touch by patients and hospital workers. ${ }^{\text {[7-10] }}$ Cleaning and/or disinfection of the surface have been used in hospitals to prevent surface contamination. ${ }^{[9-11]}$ Although cleaning may decrease the levels of surface contamination, it is difficult to eradicate entirely because firstly, the bacteria may be strongly adherent to the surface ${ }^{[12]}$ and even a small number of residual bacteria will quickly reproduce to significant numbers if environmental conditions are favourable. ${ }^{[13]}$ Secondly, it is not easy to implement the cleaning and disinfection schemes thoroughly. Thus, it is necessary to develop effective and applicable alternatives to inhibit pathogen transmission in hospitals. 
In order to prevent hospital surface contamination, a variety of techniques have been suggested including polyethylene glycol coatings, ${ }^{[14]}$ easy-cleaning surfaces, ${ }^{[15,16]}$ silver or copper coated surfaces, ${ }^{[17-20]}$ and photosensitization surfaces using light activated antimicrobial agents (LAAAs). ${ }^{[21-}$ ${ }^{23]}$ Among them, surface treatment using LAAAs is considered promising because it can be easily applied to polymers which are widely used as hospital surfaces and in medical devices including tracheal or urinary catheters, and tubes for intravenous drips. ${ }^{[24]}$

Crystal violet (CV), methylene blue (MB) and toluidine blue O (TBO) dyes are well known LAAAs. [25, 26] The agents produce reactive singlet oxygen $\left({ }^{1} \mathrm{O}_{2}\right)$ and reactive oxygen species (ROS) when exposed to a light source and these are toxic to bacteria. ${ }^{[25,27]}$ The free radicals and ROS cause adverse effects in bacteria such as loss of membrane integrity, inactivation of enzymes, and DNA damage. ${ }^{[28,}$ ${ }^{29]}$ The production of ${ }^{1} \mathrm{O}_{2}$ and $\mathrm{ROS}$ is directly related to light intensity, and a $\sim 600 \mathrm{~nm}$ laser was shown to be more efficient than white light from a hospital lamp due to higher flux. Additionally, ${ }^{[30,31]}$ the LAAAs have somewhat lower or no antimicrobial activity in the absence of light. ${ }^{[32]}$ The antimicrobial activity of a LAAA is dependent on the concentration of the agent, the exposure time, and the intensity of light, and they are typically more effective against Gram-positive bacteria compared to Gramnegative bacteria. ${ }^{[32,33]}$

With respect to surface application of LAAAs, previous studies showed $\mathrm{MB}$, TBO, and CV dyes can be physically incorporated into polymers through a swell-encapsulation-shrink process and the

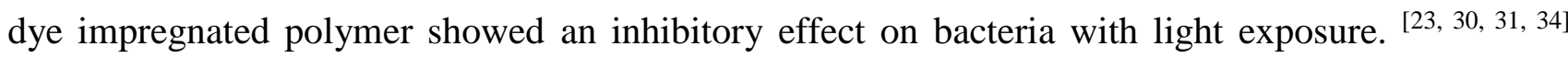
Moreover, it was shown that in the TB or MB impregnated polymer, additional encapsulation of $2 \mathrm{~nm}$ gold $(\mathrm{Au})$ nanoparticles (NPs) significantly enhanced the photobactericidal activities. ${ }^{[35]}$ According to Noimark et al., (2012), the enhancement in the photosensitization of the dye impregnated polymer can be attributed to an increased dye triplet state production when $2 \mathrm{~nm}$ Au NPs are present. ${ }^{[34]}$

Recently, studies of white light activated antimicrobial surfaces have been conducted because laser technology is not practical for use in the sterilization of touch surfaces commonly found in hospital 
environments, whereas white light, from a common hospital light source, is easily applied. In previous studies, it was shown that TBO dye polymer with Au NPs had more potent photobactericidal effects than polymer containing MB dye polymer with the NPs under identical conditions ${ }^{[30]}$ and that polymer containing CV dye with Au NPs resulted in a $>4 \log$ reduction in the numbers of both Gram-positive and Gram-negative bacteria within 6 h. ${ }^{[36,37]}$ Particularly, Noimark et al., (2014) showed that multidye process and Au NPs incorporation showed a strong photobactericidal effect at relatively low light intensity and that they also showed significant antimicrobial activity in dark conditions. ${ }^{[38]}$

In the present study, TBO dye polyurethanes with Ag NPs, Au NPs, and mixture of Ag and Au NPs (Mix Ag-Au NPs) were fabricated and tested for antimicrobial activity under white light and dark conditions. The Ag and Au NPs were synthesized in aqueous solution and they were mixed at a ratio of 1 to 1 in order to fabricate Mix Ag-Au NPs. In antimicrobial testing, the materials were potent against $E$. coli under white light and surprisingly, also in the dark. As far as we are aware, this is the first study to show that Ag NP enhances the effectiveness of a light activated dye. The modified polyurethane produced was one of the most potent antimicrobial surfaces ever reported, with extraordinary white light and dark kill of E. coli.

\section{Results and Discussion}

\subsection{Synthesis of Nanoparticles}

Transmission electron microscopy (TEM) and energy-dispersive X-ray spectroscopy (EDS) were used in order to characterize the NPs. The NPs were made by citrate reduction of boiling aqueous solution of $\mathrm{HAuCl}_{3}$ and/or $\mathrm{AgNO}_{3}$. As shown in Figure 1 (a) and (b), both $\mathrm{Ag}$ and $\mathrm{Au} \mathrm{NPs}$ had polydisperse sizes, respectively, and they are non-agglomerated. The mean size of Ag NPs was $22.4 \pm$ $16.7 \mathrm{~nm}$ with median of $22 \mathrm{~nm}$, and interquartile range (IQR) of $24 \mathrm{~nm}$ and for Au NPs, it was $34.4 \pm$ $12.5 \mathrm{~nm}$ with median of $34 \mathrm{~nm}$, and IQR of $12 \mathrm{~nm}$ (Figure S1 (a) and (b): Supporting information). They showed a variety of morphologies such as rod, sphere, ellipse, and triangle. EDS analysis confirmed that all of peaks were assigned to $\mathrm{Ag}$ and $\mathrm{Au}$, respectively and impurities were not detected 
(Figure 1 (d)). For Mix Ag-Au NPs, TEM and size analyses showed that most of the mixed NPs were agglomerated (Figure 1 (c)) and the mean size of the agglomerations was $252 \pm 197.5 \mathrm{~nm}$ with median of $175 \mathrm{~nm}$, and IQR of $200 \mathrm{~nm}$ (Figure S1 (c)). In EDS analysis (Figure 1 (d)), peaks, showed both Ag and $\mathrm{Au}$, were confirmed in the particles.

The UV-vis absorption spectra (Figure S2) of the Ag NPs suspension exhibited a peak at $409 \mathrm{~nm}$, and the peak for Au NPs suspension was shown at $526 \mathrm{~nm}$. In the mixture of Ag and Au NPs, a dual peak, which represent the individual Ag and Au NPs respectively, was shown.

\subsection{Characterization of White Light-Activated Antimicrobial Surfaces}

A simple swell-encapsulation-shrink process was employed to incorporate $\mathrm{TBO}$ dye, $\mathrm{Au}$, and $\mathrm{Ag}$ NPs into polyurethane using acetone as a swelling solution. In the swell-encapsulation process, the TBO molecules and NPs in the acetone penetrate the polyurethane matrix as it swells, and the polyurethane then shrinks when it is removed from the solution. The TBO molecules and NPs remain inside of the polyurethane matrix.

The polyurethane sample with various dying times were analyzed using fluorescence microscopy. The TBO fluorescence of thinly sliced sample side sections were imaged using CCD camera and the images were analyzed in order to confirm extension of the dye diffusion throughout the sample. Figure 2 shows the diffusion of TBO dye inside polyurethane with increasing time. About two thirds of the sliced sample was shown on left side of each image and it provides the gradient of dye diffusion inside the polyurethane. Colour scale bar corresponds from low (black) to high fluorescence (white). As shown in the fluorescence images, at the beginning, absorption of the dye was predominantly near to the surface. With increasing immersion time, the dye diffused to throughout the sample and it was saturated after $1 \mathrm{~h}$. This trend was shown in all of the treated samples, and there was no difference in fluorescence between $1 \mathrm{~h}$ and $24 \mathrm{~h}$ dyed samples.

To determine NPs uptake from NPs suspension to polyurethane, The UV-vis spectra of NPs suspension were measured before and after swell-encapsulation-shrink process. The polymer sample 
was immersed in a mixture of acetone $(9 \mathrm{~mL})$ and NPs $(1 \mathrm{~mL})$ for $24 \mathrm{~h}$. As shown Table 1, $8 \%$ of Ag NPs in the suspension was absorbed to polyurethane sample and 32 and $25 \%$ of Au NPs and Mix AgAu NPs were permeated to the polymer, respectively (Figure S3).

In order to produce antimicrobial polyurethane, samples were treated using TBO solutions containing Ag NPs, Au NPs, and Mix Ag-Au NPs for 24 h, and the UV-vis absorbance spectra of samples were measured over the wavelengths $350-950 \mathrm{~nm}$. Figure 3 shows the absorbance spectra of control and treated samples. All of the treated samples gave a main absorption peak at $636 \mathrm{~nm}$ with the Ag NPs incorporated sample of highest intensity. However, the shoulder peaks of NPs embedded samples were different depending on the type of NPs (Ag: 595 nm, Au: 590 nm, Mix Ag-Au NPs: 592 $\mathrm{nm}$ ), and spectra of their absorbance were relatively broad, compared to that of TBO dyed sample. These indicated that the presence of $\mathrm{Ag}$ or $\mathrm{Au}$ NPs affected the position of the spectra feature. Additionally, the absorption of the Ag or Au NPs encapsulated samples was not confirmed. This is because of the low concentration of NPs in the sample or high absorbance of TBO.

Water contact angle and elastic modulus of untreated, control, and TBO and NP treated polyurethane samples were measured. As shown in Table 2, untreated polyurethane gave water contact angles of $99.9^{\circ}$, indicating hydrophobicity. However, after $24 \mathrm{~h}$ swell-encapsulation, the contact angles of the samples decreased. In particular, the reduction on the control sample was the highest and it was approximately $29^{\circ}$. After the treatment, all of the samples became hydrophilic except for the Ag NPs incorporated samples.

Strain-stress tests were conducted in order to determine the physical change of polyurethane samples driven by swell-encapsulation. Elastic modulus is a number which represents the resistance of samples against elastic deformation. Swell-encapsulation caused a slight reduction of elastic modulus for all of the samples and the maximum reduction was approximately 9.1 MPa (Table 2). These results indicate that durability of the modified polyurethane against external force was lower compared to unmodified polyurethane, although still in a usable range. This trend is in agreement with previous research. ${ }^{\text {[24] }}$ 
The reduction of physical properties resulted from the swelling process because polyurethane is susceptible to acetone on long term and repeated exposures. ${ }^{[39]}$ In addition, it was confirmed that NPs incorporation relieved the reduction of water contact angle and elastic modulus, and Ag NPs were more efficient than Au NPs in this respect.

\subsection{Antimicrobial Test}

The antimicrobial activity of the control, TBO dyed polyurethane samples, and TBO dyed polyurethane samples containing Ag or Au NPs alone, and Mix Ag-Au NPs under white light and dark conditions was tested against a representative strain of the Gram-negative bacterium, Escherichia coli, a key causative agent of HAI. ${ }^{[3]} 25 \mu \mathrm{L}$ of this bacterial suspension (containing $1.1 \times 10^{5} \mathrm{CFU}$ ) was inoculated onto the surface of each sample, and exposed to white light or incubated in the dark at room temperature for the same period of time. Figure 4 shows the distribution of white light intensity. Using a lux meter (LX-101, Lutron Inc., Coopersburg, PA, USA), it was measured at a distance of $30 \mathrm{~cm}$ from the light source. The intensity of the light ranged from 3900 to 5300 lx. In the dark, the light was completely blocked (0 lx).

Figure 5 (a) and (b) show the antimicrobial activity of the samples after $3 \mathrm{~h}$ and $24 \mathrm{~h}$ incubation in the dark. After $3 \mathrm{~h}$, no reduction in the numbers of viable bacteria was observed on the surfaces of the control material (polyurethane alone), polyurethane with TBO only, and polyurethane containing TBO and Au NPs. However, a statistically significant $(\mathrm{P}<0.01)$ decrease in the number of viable bacteria was observed on the materials containing either TBO and Mix Ag-Au NPs (0.34 log reduction in bacterial numbers) or TBO with Ag NPs alone (0.49 log reduction). After $24 \mathrm{~h}$ in the dark, the control material, polyurethane with TBO only, and polyurethane with TBO and Au NPs showed no significant reduction in bacterial viability whereas polyurethane containing TBO and Mix Ag-Au NPs or TBO with Ag NPs alone showed a significant reduction in the numbers of bacteria to below the limit of detection (P-value $<0.01$, detection limit: below $10^{2} \mathrm{CFU} / \mathrm{mL}$ ). 
Additionally, in experiments of polyurethane containing NPs only, no reduction in the number of viable bacteria was confirmed after $3 \mathrm{~h}$ incubation in dark (Figure 6 (a)). However, after $24 \mathrm{~h}$ in dark condition, a significant reduction was observed on polyurethane with Mix Ag-Au NPs only (P-value $<0.01,2.39 \log$ reduction) or Ag NPs only (P-value $<0.01$, detection limit: below $10^{2} \mathrm{CFU} / \mathrm{mL}$ ) (Figure $6(b))$.

At $3 \mathrm{~h}$ incubation in dark, it was observed that polyurethanes containing the NPs and TBO have stronger dark kill than polyurethane with NPs only (P-value $<0.01)$ although the difference between TBO/Ag NPs and Ag NPs only was not observed at 24 incubation in dark. These results indicate that although the NPs embedded in surface of polyurethane show an antimicrobial activity, a synergistic effect induced by incorporation of TBO and NPs produce stronger antimicrobial activity.

Silver and gold NPs used in this study are widely known antimicrobial inorganic material and they boast a broad antimicrobial spectrum. ${ }^{[40,41,42,45,46,47]}$ However, the antimicrobial intensity of them is clearly different. According to a previous study, ${ }^{[48]} \mathrm{Ag}$ NPs have some intrinsic antimicrobial activity as $\mathrm{Au}$ NPs were required at 200 times higher concentration than that of $\mathrm{Ag}$ in order to get comparable the efficiency. This trend is in agreement with our experimental results.

Figure 5 (c) shows the antimicrobial activities of control and modified samples under white light. In contrast to the samples incubated in the dark, all of the modified samples demonstrated strong photobactericidal activities after $3 \mathrm{~h}$ white light exposure (all modified samples: $\mathrm{P}<0.01$ ). Compared to the control sample, $0.74 \log$ and $1.9 \log$ reductions in the numbers of viable bacteria were observed on polyurethane/TBO and polyurethane/TBO/Au NPs, respectively. The materials containing TBO and Mix Ag-Au NPs or TBO with Ag NPs alone showed a reduction in the numbers of viable bacteria to below the detection limit after $3 \mathrm{~h}$ exposure to white light. After $3 \mathrm{~h}$ white light exposure, no difference in photobactericidal activity between polyurethane containing Mix Ag-Au NPs and polyurethane containing Ag NPs alone was apparent as in both cases, the numbers of viable bacteria were below the detection limit. Therefore, $2 \mathrm{~h}$ white light exposure was tested. As shown in Figure 5 
(d), the photobactericidal activity of Mix Ag-Au NPs incorporated sample at $2 \mathrm{~h}$ was much weaker than that of $3 \mathrm{~h}$ light exposure giving a reduction in bacterial numbers of only $1.48 \mathrm{log}$. However, the sample including Ag NPs still displayed potent photobactericidal activity after only $2 \mathrm{~h}$ of light exposure resulting in a $4.2 \log$ reduction in the number of viable bacteria. The increased bactericidal activity displayed by the material containing Ag alone is presumably the result of a higher Ag content compared to the material containing the Mix Ag-Au NPs.

In previous studies, it was reported that both free radical and ROS have a short diffusion distance of $<220 \mathrm{~nm} .{ }^{[38,49,50]}$ Thus, it is speculated that TBO dye and NPs impregnated within the polyurethane are redundant in terms of their contribution to antimicrobial activity. Only the dye and NPs incorporated near to the polyurethane surface would be able to act as a photosensitiser able to kill surface-colonising bacteria.

Incorporation of NPs into polyurethanes without TBO did not reinforce photobactericidal activity (Figure 6 (c)) while incorporation of NPs into the samples containing TBO successfully enhanced the photobactericidal activity. This indicates that there was an interaction between the dye molecules and NPs that induce an enhancement of the activity.

The photobactericidal activity can explained as follows; under white light condition, TBO molecules in polyurethane are excited to a high energy triplet state from a low ground state. The triplet state dye reacts via type I (biomolecular reaction) or/and type II (reaction of molecular oxygen) photochemical pathways to produce ROS and ${ }^{1} \mathrm{O}_{2}$ leading to bacterial death. It was speculated that NP incorporation enhances type I or type II photochemical reaction of the dye molecules. ${ }^{[36]}$ To determine enhancement of ${ }^{1} \mathrm{O}_{2}$ generation, measurement of singlet oxygen was conducted. Fufuryl alcohol, which has been widely used as a chemical trap of ${ }^{1} \mathrm{O}_{2}$, was used. ${ }^{[61]} 200 \mu \mathrm{L}$ DI water containing $5.75 \times 10^{-8} \mathrm{M}$ of fufuryl alcohol used at each sample to measure the ${ }^{1} \mathrm{O}_{2}$ concentration. At $222 \mathrm{~nm}$ wavelength, the consumption of fufuryl alcohol was monitored because the loss of fufuryl alcohol attributes to reaction with ${ }^{1} \mathrm{O}_{2}$. Although after $3 \mathrm{~h}$ of white light exposure, the generation of ${ }^{1} \mathrm{O}_{2}$ was observed on treated 
samples, the concentrations of ${ }^{1} \mathrm{O}_{2}$ produced from TBO only dyed polyurethane, TBO dyed polyurethane with Au NPs, TBO dyed polyurethane with Mix Ag-Au NPs, and TBO dyed polyurethane with Ag NPs were similar. This result indicates that the NPs incorporation did not enhance type II photochemical reaction to produce ${ }^{1} \mathrm{O}_{2}$. Thus, it is speculated that the enhancement of photobactericidal activity resulted from increase of type I photochemical reaction caused by NPs.

A similar effect in terms of light activated antimicrobial dye agent and Au NPs was shown by previous researches, ${ }^{[30,35,37]}$ whereas in case of Ag NPs, it was not reported. Our experimental results showed that Ag NPs incorporated sample had > 2.54 log higher photobactericidal activity than Au NPs under $3 \mathrm{~h}$ of white light exposure, and even showed a potent photobactericidal effect after $2 \mathrm{~h}$ resulting in a $4.2 \log$ reduction in the number of viable bacteria. This indicates that Ag NPs are better at enhancing photobactericidal activity than Au NPs.

Our study shows for the first time that encapsulation of Ag NP in TBO impregnated polymer significantly enhances photobactericidal activity. To validate the antimicrobial efficacy of Ag NPs incorporated white light-activated antimicrobial surface (WLAAS), photobactericidal activity was compared with the results of previous studies. The study of Ag NPs coated titania thin film showed that Ag NPs could enhance photobactericidal activity of the film. When tested against E. coli using a white light intensity of $5000 \mathrm{~lx}$, the film showed a lethal photosensitization, producing $4.4 \log$ reduction in bacterial viability within 6 h. ${ }^{[52]}$ Our work shows that the combination of Ag NPs and TBO dye produces stronger photobactericidal activities against bacteria than that of Ag NPs and titania because with a white light intensity of average 4400 lx, our combination reduced the numbers of viable bacteria to below the detection limit within $3 \mathrm{~h}$. Moreover, compared to multi-dyed WLAAS ${ }^{[37]}$ and zinc oxide NPs incorporated polymer ${ }^{[53]}$ which our group has previously shown to have excellent antimicrobial activity, Ag NPs with TBO incorporated surface was able to reduce the number of bacteria to below the detection limit in half the time in white light of comparable intensity. Similarly, 
in the dark, TBO plus Ag NPs also showed unprecedented antimicrobial activity. To the best of our knowledge, this is the most potent WLAAS reported to date.

It is expected that Ag incorporated polymer could be used to develop antimicrobial surfaces for clinical environments and also for various appliances such as keyboards, mobile phones, and tablet covers, and toilet and kitchen surfaces. For real world application of the polymer, adverse effects on human health should be considered. As Ag NPs used in this study have been widely used in food industry, medicine, and water quality control, ${ }^{[54-60]}$ studies of their toxicity have been extensively conducted. The toxicity of Ag NPs is dependent on many factors, including size, dosage, and exposure time. ${ }^{[61]}$ In vivo tests against mammals demonstrated that Ag NPs only had toxic effects at long term (28-90 days) and high concentration dosages (inhalation: $>10^{4}$ particles $/ \mathrm{cm}^{3}$, ingestion: $>30 \mathrm{mg} / \mathrm{kg}$ ). ${ }^{\text {[62-64] }}$ Although TBO is classified as non-hazardous material by the Occupational Safety and Health Administration (OSHA) in the USA, and the National Occupational Health and Safety Commission (NOHSC) in Austria, it showed some toxicity following inhalation, ingestion or eye contact with high concentrations. ${ }^{[65-67]}$ Thus, further studies of Ag NPs and TBO incorporated WLAAS on health effect are required for real world applications.

\section{Conclusion}

Using a simple swell-encapsulation shrink process, TBO in combination with Ag NPs and Au NPs, were incorporated into a key polymer used in healthcare applications. Incorporation of Ag NPs and TBO dyed into polyurethane resulted in potent WLAASs that not only induced the lethal photosensitisation of $E$. coli within $3 \mathrm{~h}$, but demonstrated strong bactericidal activity under dark conditions $(24 \mathrm{~h})$, reducing bacterial viability to below the detection limit. These WLAASs show unprecedented antimicrobial activity, achieving high bacterial kills under dark conditions, in addition to a light-activated kill mechanism for enhanced bactericidal activity. It is anticipated that these potent WLAASs will be used in healthcare applications to reduce surface bacterial contamination and thus reduce the risk of HAIs 


\section{Experimental Section}

\subsection{Preparation of Chemical Stock Solutions}

Solution A: $49.2 \mathrm{mg}(0.125 \mathrm{mM})$ of $\mathrm{HAuCL}_{4} \cdot 3 \mathrm{H}_{2} \mathrm{O}$ (Gold (III) chloride trihydrate, Sigma-Aldrich, St. Louis, MO, USA) was dissolved in $25 \mathrm{~mL}$ of deionised (DI) water to get a $5 \mathrm{mM}$ solution.

Solution B: $45 \mathrm{mg}(0.26 \mathrm{mM})$ of $\mathrm{AgNO}_{3}$ (Silver nitrate, Sigma-Aldrich, St. Louis, MO, USA) was dissolved in $50 \mathrm{~mL}$ of DI water to produce an approximately $5 \mathrm{mM}$ solution.

Solution C: $294.7 \mathrm{mg}(1 \mathrm{mM})$ of $\mathrm{Na}_{3} \mathrm{C}_{6} \mathrm{H}_{5} \mathrm{O}_{7} \cdot 2 \mathrm{H}_{2} \mathrm{O}$ (tri-sodium citrate dihydrate, Hopkin \& Williams Ltd, London, UK) was dissolved in $50 \mathrm{~mL}$ of DI waster to form a $20 \mathrm{mM}$ solution.

\subsection{Synthesis of Gold (Au) Nanoparticles (NPs)}

$1 \mathrm{~mL}$ of solution A was mixed with $18 \mathrm{ml}$ of DI water and heated with constant stirring. After the mixture was boiled for $\sim 2 \mathrm{~min}, 1 \mathrm{~mL}$ of solution $\mathrm{C}$ was added. With constant stir, the mixture was boiled for a further $30 \mathrm{~min}$ and then allowed to cool. During the process, a scarlet color developed.

\subsection{Synthesis of Silver (Ag) Nanoparticles (NPs)}

$1 \mathrm{~mL}$ of solution $\mathrm{B}$ was mixed with $18 \mathrm{~mL}$ of DI water and heated with constant stir. After the mixture was boiled for $\sim 2 \mathrm{~min}, 1 \mathrm{~mL}$ of solution $\mathrm{C}$ was added. With constant stir, the mixture was boiled for a further $30 \mathrm{~min}$ and then allowed to cool. The development of a yellow colour was observed during the process.

\subsection{Mixture of Ag and Au NPs (Mix Ag-Au NPs)}

Mixture of Ag and Au NPs (Mix Ag-Au NPs) were prepared by mixing solutions of Ag and Au NPs. The combination was conducted at a ratio of 1 to 1 in volume. The color of the Mix Ag-Au NPs solution was purple.

\subsection{Preparation of White Light-Activated Antimicrobial Surface}

Toluidine blue O (TBO, Sigma-Aldrich, St. Louis, MO, USA) (Figure S4) solutions were prepared at concentration of $600 \mathrm{ppm}$ in a mixture of acetone $(9 \mathrm{~mL})$, and DI water or NPs $(1 \mathrm{~mL})$. The solutions were sonicated in an ultrasound bath for $5 \mathrm{~min}$ in order to ensure complete dissolution of TBO powder. 
Polyurethane $(1.0 \times 1.0 \mathrm{~cm})$ were immersed in $10 \mathrm{~mL}$ of TBO solutions and left to swell in the dark for $24 \mathrm{~h}$. The polyurethane were recovered from the TBO and washed 2 times using DI water and then airdried for $24 \mathrm{~h}$ in the dark (Figure S5 (a)). The samples were prepared as follows: TBO only, TBO with Au NPs, TBO with Ag NPs and TBO with Au/Ag NPs.

Additionally, NPs encapsulated polyurethane samples without TBO were prepared as follows: polyurethane with Au NPs, polyurethane with Ag NPs and polyurethane with Au/Ag NPs.

\subsection{Mechanical Properties}

Equilibrium water contact angle measurement on the polyurethane samples was conducted. A droplet $(\sim 5 \mu \mathrm{L})$ of deionised water was dropped onto the surface of the samples by gravity from a gauge 27 needle, the samples were photographed side on and the images was analyzed using Surftens 4.5 software.

Elastic stress of the samples was measured using material testing and inspection device (AGS-X, Kyoto, Japan) which is about $10 \mathrm{kN}$ in capacity. The tensile grips action was used for samples with size of $0.8 \mathrm{~mm}$ (thickness) $\times 3 \mathrm{~mm}$ (width). From initial distance $30 \mathrm{~mm}$ between the grips the samples were stretched at a speed of $300 \mathrm{~mm} / \mathrm{min}$ until final sample size equal to 5 times of initial one. The result was analyzed using Trapezium Lite X software.

\subsection{Antimicrobial Test}

The antimicrobial activities of the samples were tested against Escherichia coli (strain ATCC 25922) which was stored at $-70^{\circ} \mathrm{C}$ in Brain-Heart-Infusion broth (Oxoid Ltd., Hampshire, England, UK) containing 20\% (v/v) glycerol and propagated on MacConkey agar (Oxoid Ltd., Hampshire, England, UK). $10 \mathrm{~mL}$ of BHI broth was inoculated with one bacterial colony and cultured at $37^{\circ} \mathrm{C}$ with shaking at $200 \mathrm{rpm}$. After incubation for $18 \mathrm{~h}$, the bacteria were harvested by centrifugation, washed 2 times using phosphate buffered saline (PBS), and serially diluted in PBS for viable counts. The inoculum contained $4.6 \times 10^{6}$ colony forming units per $\mathrm{mL}(\mathrm{CFU} / \mathrm{mL}) .25 \mu \mathrm{L}$ of this bacterial suspension (containing $1.1 \times 10^{5} \mathrm{CFU}$ ) was inoculated on to the surface of each sample and covered with a sterile 
glass cover slip $(2.2 \times 2.2 \mathrm{~cm})$ to ensure good contact between the bacteria and the sample surface. The samples were placed into plastic petri dishes containing moistened filter paper to maintain humidity and exposed to white light while an identical set of samples was maintained in the dark (Figure S5 (b)). After light exposure, the samples and cover slips were placed into $450 \mu \mathrm{L}$ of PBS, and mixed using a vortex mixer for $1 \mathrm{~min}$. The bacterial suspension was serially diluted, plated onto MacConkey agar, and incubated at $37^{\circ} \mathrm{C}$ for $24 \mathrm{~h}$. The colonies that grew on the plates were counted.

\subsection{Material Characterization}

TEM (JEM-2100, JEOL Inc., Peabody, MA, USA) with EDS was used to confirm the size, morphology, and chemical composition of synthesized NPs.

The UV-vis absorption spectra against NPs suspensions, control, and treated samples were measured using UV-Vis Spectrometer (PerkinElmer Inc., Winter St., CT, USA). Absorption was measured from 350 to $900 \mathrm{~nm}$ (Figure S6).

For investigating the diffusion of TBO inside polyurethane, flat samples were dyed for 5,30 , and $60 \mathrm{~min}$. Their side sections were sliced into $400 \mu \mathrm{m}$ thickness using a scalpel and were mounted on glass slides for fluorescence imaging. The samples were imaged using an inverted fluorescence microscope (Model-IMT-2, Olympus Ltd., Tokyo, Japan) with cooled scientific-grade 16-bit digital CCD camera (Model- PIXIS 512, Roper industries Ltd., Sarasota, FL, USA) operated by Win-Spec software. The samples were detected using fluorescence excitation with a $633 \mathrm{~nm}$ laser. Fluorescence was detected using a bandpass filter centered at $660 \mathrm{~nm}$ (model-660DF30, Omega Optical Inc., Brattleboro, VT, USA). The images were subsequently analyzed using WinSpec/32 (Roper industries Ltd., Sarasota, FL, USA) and ImageJ software (\ \http://rsbweb.nih.gov/ij/).

To determine the amount of NPs encapsulated into polyurethane sample, The UV-vis absorbance spectra of NP suspension were measured before and after swell-encapsulation-shrink process. The polyurethane sample was immersed in a mixture of acetone $(9 \mathrm{~mL})$, and NPs $(1 \mathrm{~mL})$ for $24 \mathrm{~h}$. The 
comparison of absorbance at 409 (Ag NPs) and $526 \mathrm{~nm}$ (Au NPs) or both at 409 and $526 \mathrm{~nm}$ (Mix AgAu NPs) was enable determination of the amount of NP absorbed in the polymer.

The uptake rate of NPs from NPs suspension to polyurethane sample was calculated as follow;

$$
\text { Uptake rate }(\%)=100 \times\left(\frac{\mathrm{AU}_{\text {before }}-\mathrm{AU}_{\mathrm{after}}}{\mathrm{AU}_{\text {before }}}\right)
$$

Where $A U_{\text {before }}$ represents the absorbance of NP suspension before polyurethane immersion in the solution and $\mathrm{AU}_{\mathrm{after}}$ shows the absorbance of NPs suspension after the polymer removal

\section{Singlet oxygen assay}

To measure the amount of singlet oxygen, $1.2 \times 10^{-5} \mathrm{M}$ of fufuryl alcohol (Sigma-Aldrich, St. Louis, MO, USA) was mixed with $40 \mathrm{~mL}$ of DI water, $200 \mu \mathrm{L}$ of the solution was inoculated on control and treated samples, and then the samples were exposed to white light source for $3 \mathrm{~h} .3$ samples were used at each condition. After the light exposure, solution $(600 \mu \mathrm{L})$ collected from three samples was loaded into quartz cuvette (volume: $~ 700 \mu \mathrm{L}$ ). At the wavelength of $222 \mathrm{~nm}$, the consumption of fufuryl alcohol was monitored using UV-vis spectrometer.

\subsection{Statistical Analyses}

T-statistics of experimental data were calculated using the SPSS statistical software, version 12.0 (SPSS, Inc., Chicago, IL, USA). 


\section{Table Legend}

Table.1. NPs uptake rate from the NPs suspension to polyurethane sample.

Table.2. Water contact angle and elastic stress on untreated, control, and treated polyurethane samples.

\section{Figure Legends}

Figure 1. TEM images of (a) Ag NPs, (b) Au NPs, and (c) Mix Ag-Au NPs, and (d) EDS analysis for synthesized Ag NPs, Au NPs, and Mix Ag-Au NPs.

Figure 2. Distribution of TBO dye after swell encapsulation for (a) $5 \mathrm{~min}$, (b) $30 \mathrm{~min}$, and (c) $60 \mathrm{~min}$ in polyurethane. Colour scale bar corresponds from low (black) to high fluorescence (white).

Figure 3. UV-vis absorption spectra of control, TBO dyed sample, and TBO dyed polyurethane containing Ag NPs, Au NPs, and Mix Ag-Au NPs.

Figure 4. Intensity distribution of white light used for irradiation of polyurethane. The intensity was measured at a distance of $30 \mathrm{~cm}$ from a $28 \mathrm{~W}$ hospital fluorescent lamp using a lux meter. Colour scale bar corresponds from low (blue) to high light intensity (red).

Figure 5. Antimicrobial activities of control and treated polyurethane samples on E. coli: (a) $3 \mathrm{~h}$ and (b) $24 \mathrm{~h}$ incubation in the dark, and (c) $3 \mathrm{~h}$ and (d) $2 \mathrm{~h}$ incubation in white light. E. coli was placed in contact with the materials and exposed to light intensities ranging from 3900 to 5300 lx. In all tests, the temperature was maintained at a constant $20{ }^{\circ} \mathrm{C}$ in an incubator.

Figure 6. Antimicrobial activities of control and treated polyurethane samples without TBO on E. coli: (a) $3 \mathrm{~h}$ and (b) $24 \mathrm{~h}$ incubation in the dark, and (c) $3 \mathrm{~h}$ incubation in white light. E. coli was placed in contact with the materials and exposed to light intensities ranging from 3900 to 5300 lx. In all tests, the temperature was maintained at a constant $20^{\circ} \mathrm{C}$ in an incubator.

Figure S1. Size distributions of Ag nanoparticles (NPs), Au NPs, and Mix Ag-Au NPs. In order to confirm the size of NPs, 20 TEM images of each NP sample were analyzed using imageJ software.

Figure S2. UV-vis absorption spectra of $\mathrm{Ag}, \mathrm{Au}$, and Mix $\mathrm{Ag}-\mathrm{Au}$ NPs suspension. $3 \mathrm{ml}$ of NPs suspension at each condition was used to confirm UV-vis absorbance spectra, and it was measured within the wavelengths $350-950 \mathrm{~nm}$.

Figure S3. UV-vis absorption of Ag NPs, Au NPs, and Mix Ag-Au NPs suspension before and after swell-encapsulation-shrink process using UV-vis spectrometer. Polyurethane sample was immersed in a mixture of acetone $(9 \mathrm{~mL})$, and DI water or NPs $(1 \mathrm{~mL})$ for $24 \mathrm{~h}$. Absorbance reductions of Ag and 
$\mathrm{Au}$ NPs suspension were measured at $409 \mathrm{~nm}$ and $526 \mathrm{~nm}$, respectively. The reduction of Mix Ag-Au NPs suspension was measured at both $409 \mathrm{~nm}$ and $526 \mathrm{~nm}$.

Figure S4. Chemical structure of toluidine blue O (TBO)

Figure S5. (a) Preparation of light activated antimicrobial surfaces and (b) antimicrobial testing Figure S6. UV-vis absorption measurement using UV-vis spectrometer 
Table.1. NPs uptake rate from the NPs suspension to polyurethane sample.

\begin{tabular}{cc}
\hline Sample & $\begin{array}{c}\text { NPs Uptake from NPs suspension } \\
\text { to polyurethane sample }(\%)\end{array}$ \\
\hline Ag NPs & $8 \pm 0.5^{\mathrm{a}}$ \\
Au NPs & $32 \pm 7$ \\
Mix Ag-Au NPs & $25 \pm 14$ \\
\hline
\end{tabular}

${ }^{a}$ Average water contact angle \pm standard deviation

Table.2. Water contact angle and elastic stress on untreated, control, and treated polyurethne samples.

\begin{tabular}{ccc}
\hline Sample & $\begin{array}{c}\text { Water contact angle } \\
\left({ }^{\circ}\right)\end{array}$ & $\begin{array}{c}\text { Elastic modulus } \\
(\mathrm{MPa})\end{array}$ \\
\hline Untreated $^{\mathrm{a}}$ & $99.9 \pm 0.7^{\mathrm{c}}$ & $15.1 \pm 1.9$ \\
Control $^{\mathrm{b}}$ & $70.5 \pm 0.9$ & $8.3 \pm 0.4$ \\
TBO only & $84.4 \pm 0.9$ & $6.0 \pm 0.6$ \\
TBO with Ag NPs & $90.6 \pm 0.8$ & $9.6 \pm 0.8$ \\
TBO with Au NPs & $88.9 \pm 1.1$ & $7.6 \pm 0.4$ \\
TBO with Mix Ag-Au NPs & $89.8 \pm 2.1$ & $8.7 \pm 0.1$ \\
\hline
\end{tabular}

${ }^{\text {a }}$ Untreated polyurethane

${ }^{\mathrm{b}}$ Acetone treated polyurethane

${ }^{c}$ Average water contact angle \pm standard deviation 

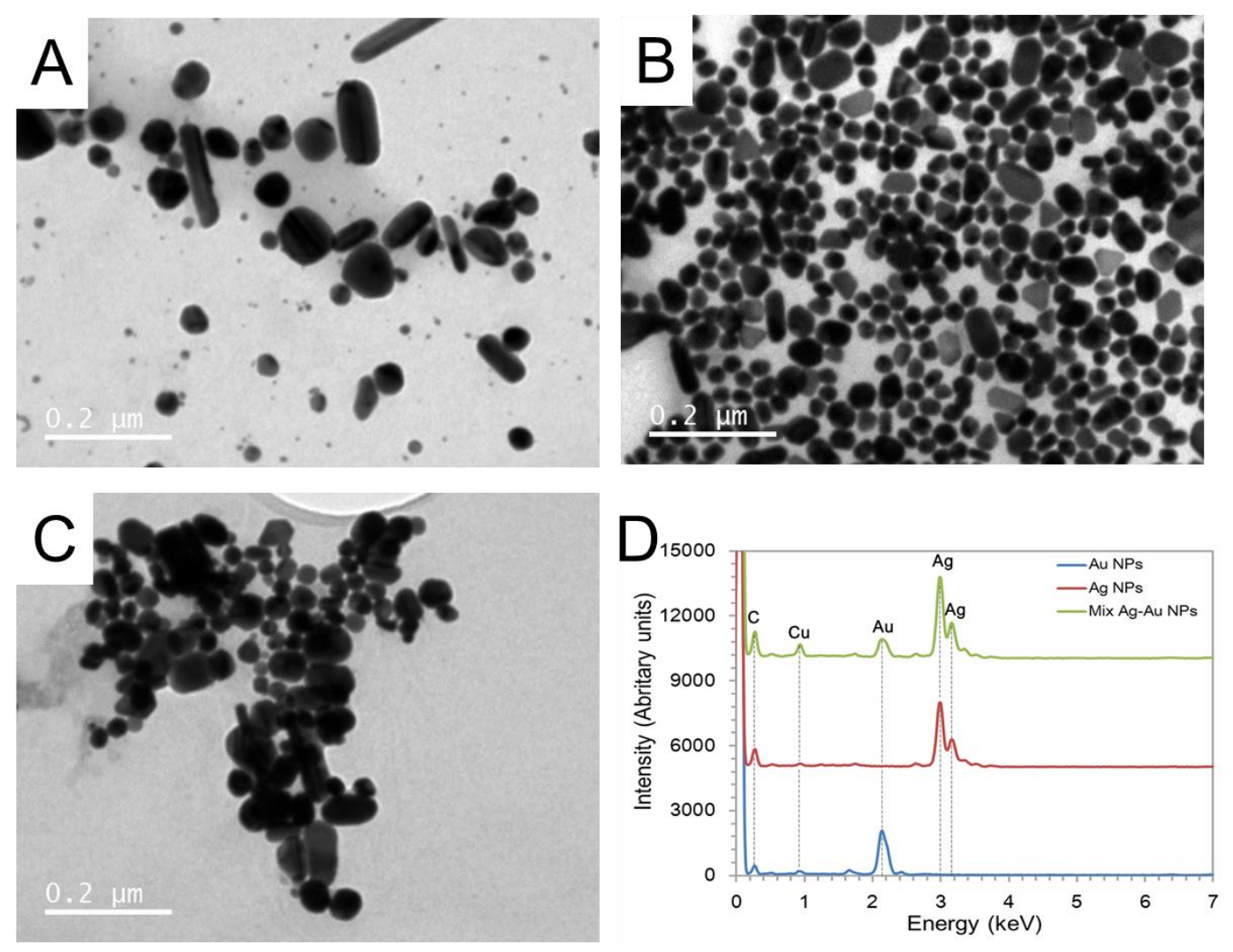

Figure 1. TEM images of (a) Ag NPs, (b) Au NPs, and (c) Mix Ag-Au NPs, and (d) EDS analysis for synthesized Ag NPs, Au NPs, and Mix Ag-Au NPs. 


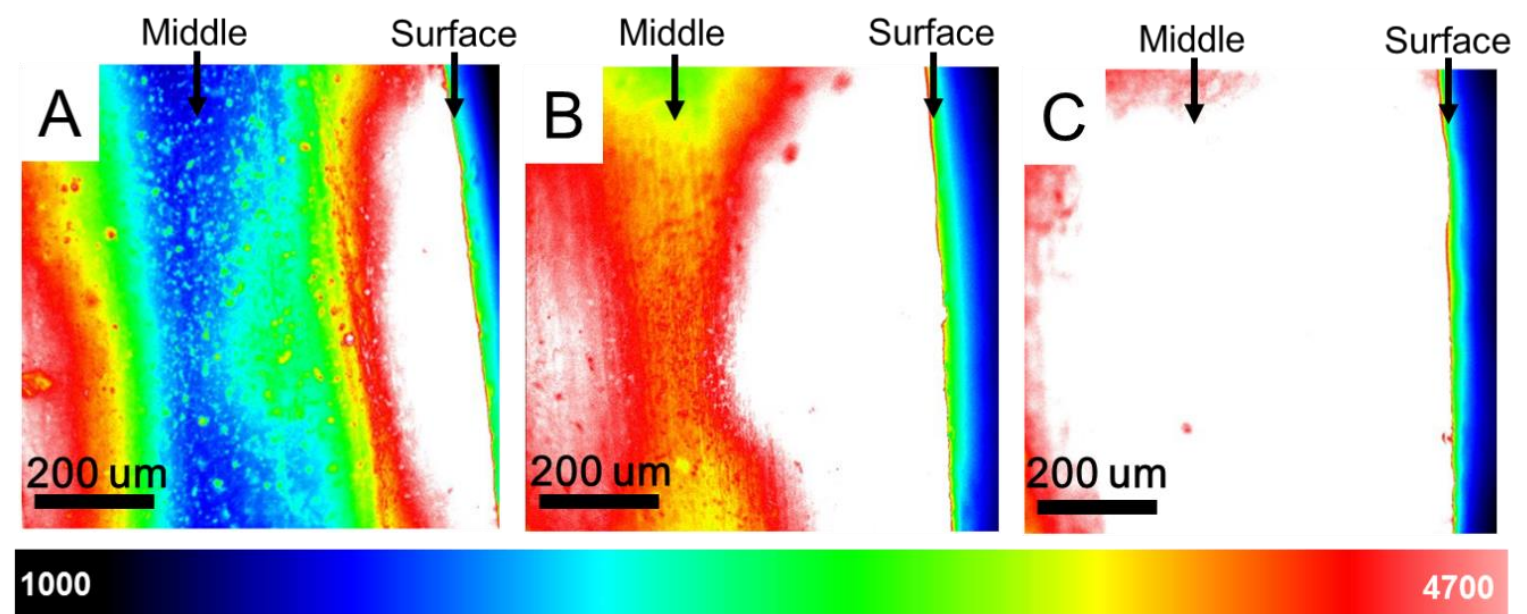

Figure 2. Distribution of TBO dye after swell encapsulation for (a) $5 \mathrm{~min}$, (b) $30 \mathrm{~min}$, and (c) $60 \mathrm{~min}$ in polyurethane. Colour scale bar corresponds from low (black) to high fluorescence (white). 


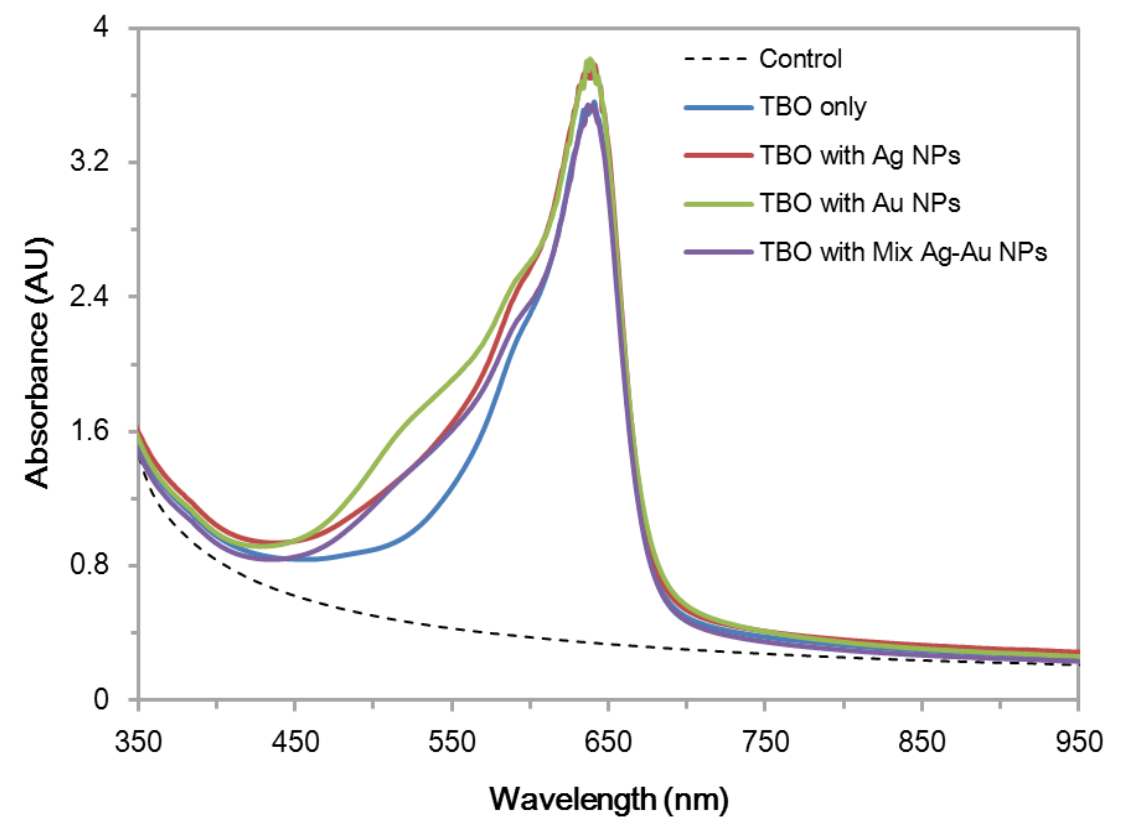

Figure 3. UV-vis absorption spectra of control, TBO dyed sample, and TBO dyed polyurethane samples containing Ag NPs, Au NPs, and Mix Ag-Au NPs. 


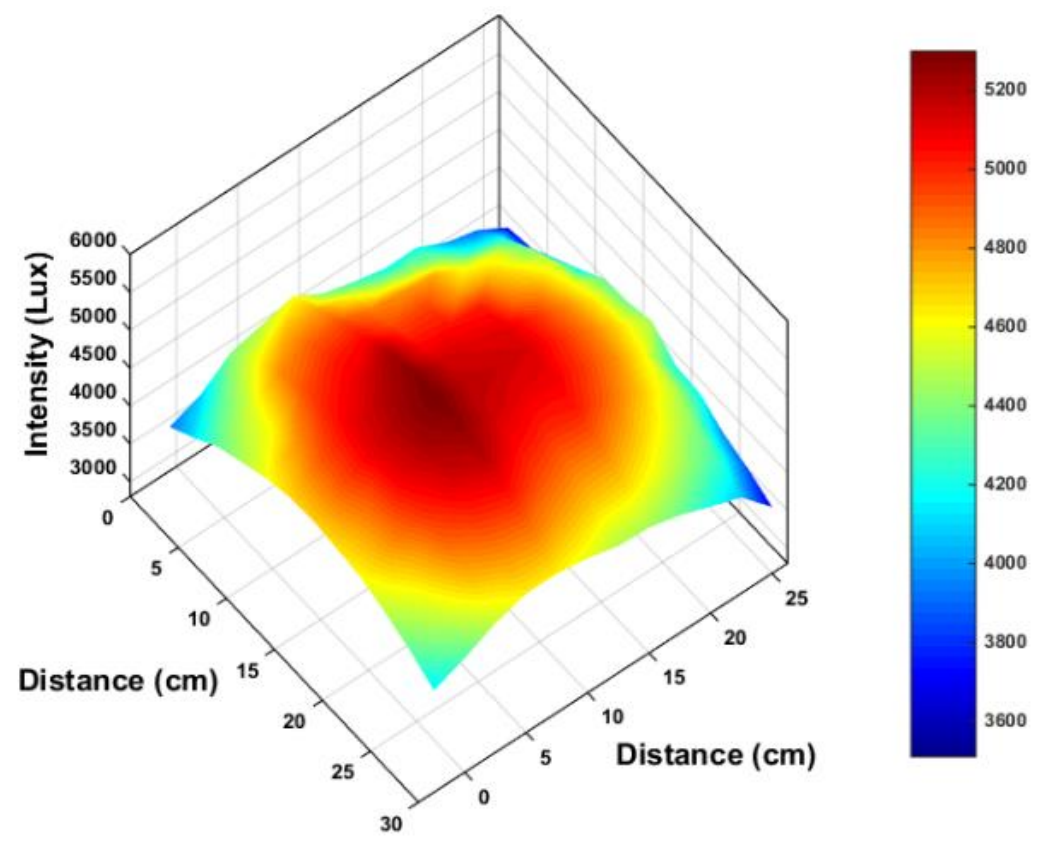

Figure 4. Intensity distribution of white light used for irradiation of polyurethane. The intensity was measured at a distance of $30 \mathrm{~cm}$ from a $28 \mathrm{~W}$ hospital fluorescent lamp using a lux meter. Colour scale bar corresponds from low (blue) to high light intensity (red). 


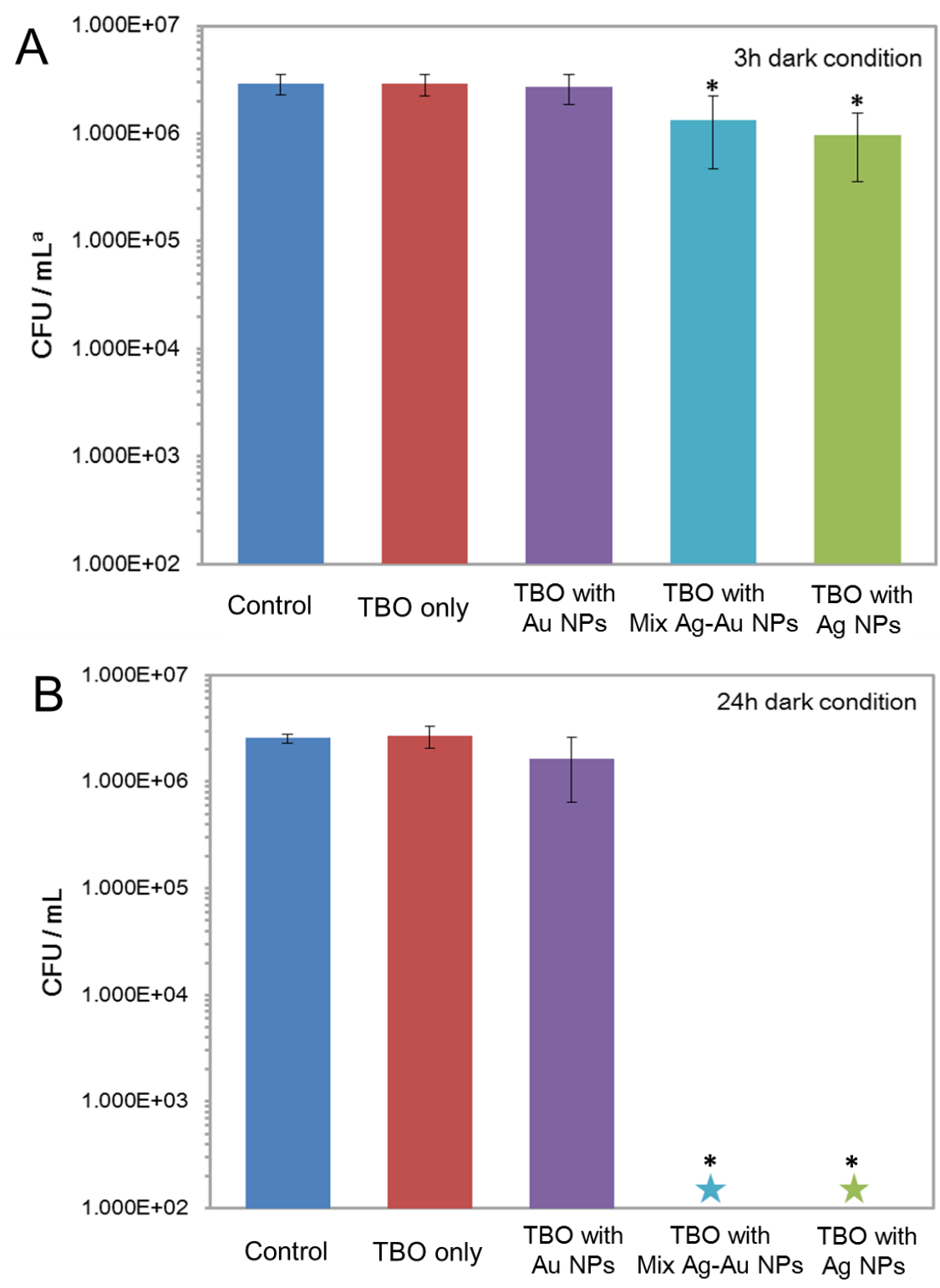




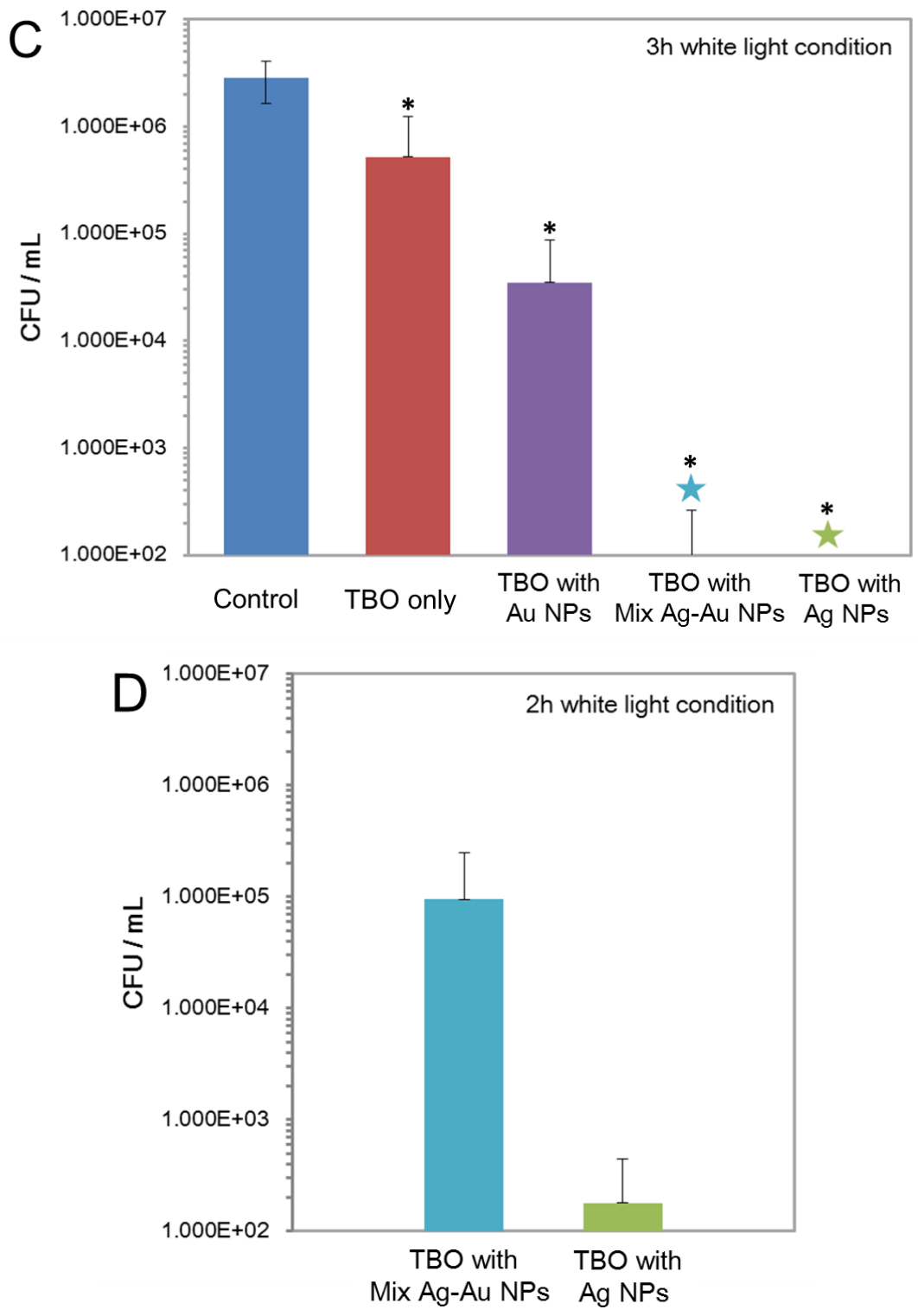

Figure 5. Antimicrobial activities of control and treated polyurethane samples on E. coli: (a) $3 \mathrm{~h}$ and (b) $24 \mathrm{~h}$ incubation in the dark, and (c) $3 \mathrm{~h}$ and (d) $2 \mathrm{~h}$ incubation in white light. E. coli was placed in contact with the materials and exposed to light intensities ranging from 3900 to 5300 1x. In all tests, the temperature was maintained at a constant $20^{\circ} \mathrm{C}$ in an incubator.

${ }^{a}$ Colony forming unit/ $\mathrm{mL}$ : Colony forming Unit (CFU) is a unit used to estimate the number of viable bacteria cells.

$*$ P-value $<0.01$

Below detection limit of $10^{2} \mathrm{CFU}$ 

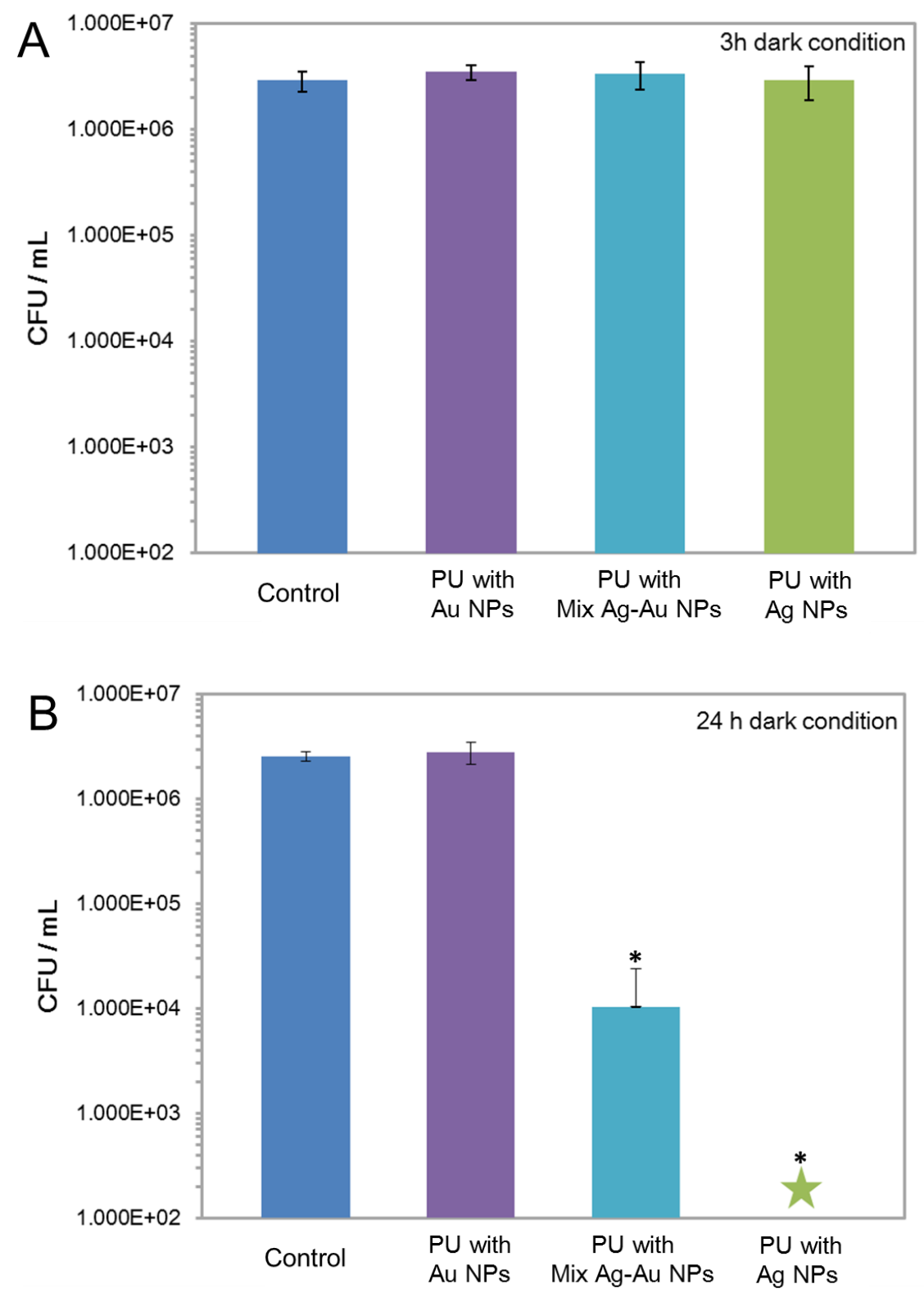


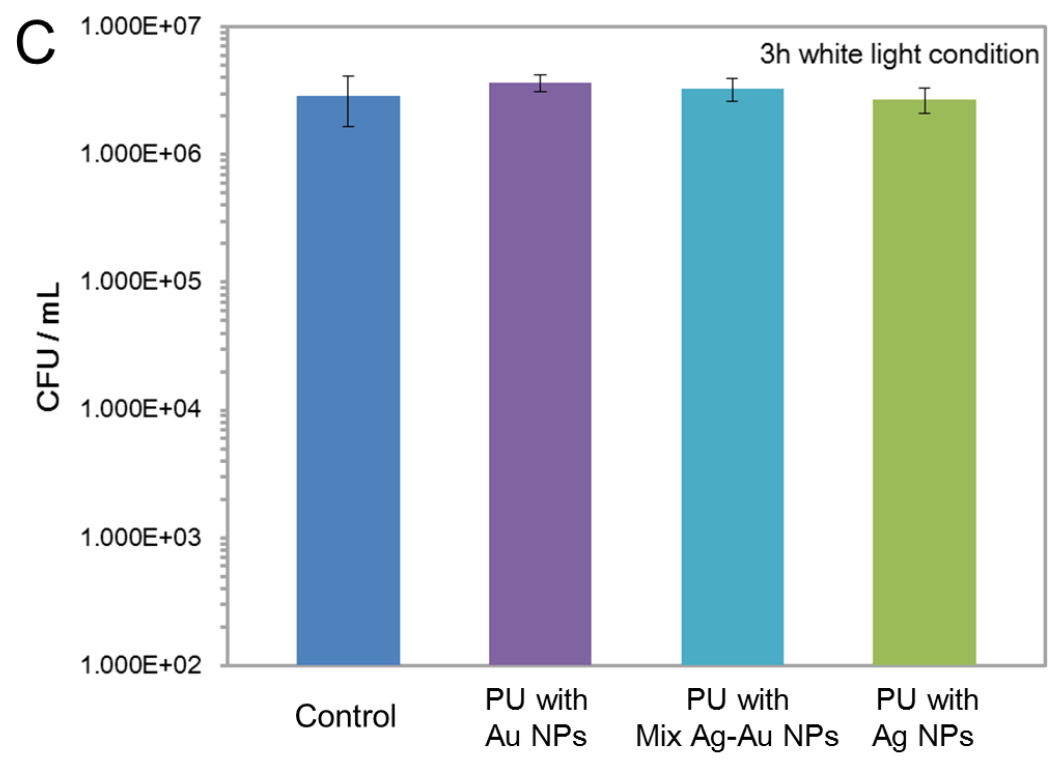

Figure 6. Antimicrobial activities of control and treated polyurethane (PU) samples without TBO on E. coli: (a) $3 \mathrm{~h}$ and (b) $24 \mathrm{~h}$ incubation in the dark, and (c) $3 \mathrm{~h}$ incubation in white light. E. coli was placed in contact with the materials and exposed to light intensities ranging from 3900 to $5300 \mathrm{~lx}$. In all tests, the temperature was maintained at a constant $20{ }^{\circ} \mathrm{C}$ in an incubator.

Below detection limit of $10^{2} \mathrm{CFU} \quad * \mathrm{P}$-value $<0.01$ 


\section{Reference}

[1] Office for national statistics, Health Stat. Q 2008, 39, 56

[2] Office for national statistics, Health Stat. Q 2008, 39, 67.

[3] House of commons, Reducing healthcare associated infection in hospitals in England, http://www.publications.parliament.uk/pa/cm200809/cmselect/cmpubacc/812/812.pdf, accessed: July, 2009.

[4] R. Plowman, Euro surveill. 2000, 5, 49.

[5] National audit office, The management and control of hospital acquired infection in acute NHS trusts in England, http://www.nao.org.uk/wp-content/uploads/2000/02/9900230.pdf, accessed: Feb, 2000.

[6] National audit office, Improving patient care by reducing the risk of hospital acquired infection: A progress report, http://www.nao.org.uk/wp-content/uploads/2004/07/0304876.pdf, accessed :July, 2004

[7] G. A. J. Ayliffe, B. J. Collins, E. J. L. Lowbury, J. R. Babb, H. A. Lilly, J. Hyg. 2009, 65, 515.

[8] K. Page, M. Wilson, I. P. Parkin, J. Mater. Chem. 2009, 19, 3819.

[9] J. M. Boyce, J. Hosp. Infect. 2007, 65, 50.

[10] D. Singh, H. Kaur, W. G. Gardner, L. B. Treen, Infect. Control Hospital Epidemiol. 2002, 23, 274.

[11] L. B. Hall, M. J. Hartnett, Public health reports 1964, 79, 1021.

[12] K. Page, M. Wilson, N. J. Mordan, W. Chrzanowski, J. Knowles, I. P. Parkin, J. Mater. Sci. 2011, 46, 6355.

[13] D. A. Ratkowsky, J. Olley, T. A. McMeekin, A. Ball, J. Bacteriol. 1982, 149.

[14] R. G. Chapman, E. Ostuni, M. N. Liang, G. Meluleni, E. Kim, L. Yan, G. Pier, H. S. Warren, G. M. Whitesides, Langmuir 2001, 17, 1225.

[15] I. P. Parkin, R. G. Palgrave, J. Mater. Chem. 2005, 15, 1689.

[16] A. Okada, T. Nikaido, M. Ikeda, K. Okada, J. Yamauchi, R. M. Foxton, H. Sawada, J. Tagami, K. Matin, Dent. Mater. J. 2008, 27, 565.

[17] H. Jiang, S. Manolache, A. C. L. Wong, F. S. Denes, J. App. Polym. Sci. 2004, 93, 1411.

[18] D. Roe, B. Karandikar, N. Bonn-Savage, B. Gibbins, J. B. Roullet, J. Antimicrob. Chemoth. 2008, 61, 869.

[19] J. O. Noyce, H. Michels, C. W. Keevil, J. hosp. infect. 2006, 63, 289.

[20] I. A. Hassan, I. P. Parkin, S. P. Nair, C. J. Carmalt, J. Mater. Chem. B 2014, 2, 2855.

[21] K. Page, R. G. Palgrave, I. P. Parkin, M. Wilson, S. L. P. Savin, A. V. Chadwick, J. Mater. Chem. 2007, 17, 95.

[22] V. Decraene, J. Pratten, M. Wilson, Appl. Environ. Microbiol. 2006, 72, 4436.

[23] J. A. Williams, G. J. Pearson, M. J. Colles, M. Wilson, Caries. res. 2004, 38, 530.

[24] S. Perni, P. Prokopovich, C. Piccirillo, J. Pratten, I. P. Parkin, M. Wilson, J. Mater. Chem. 2009, 19, 2715.

[25] M. Wainwright, J. Antimicrob. Chemoth. 1998, 42, 13.

[26] R. Docampo, S. N. J. Moreno, F. S. Cruz, Mol. Biochem. Parasit. 1988, 27, 241. 
[27] M. R. Hamblin, T. Hasan, Photochem. Photobiol. Sci. 2004, 3, 436.

[28] N. L. Oleinick, H. H. Evans, Radiat. Res. 1998, 150, S146.

[29] E. Ben-Hur, A. C. E. Moor, H. Margolis-Nunno, P. Gottlieb, M. M. Zuk, S. Lustigman, B. Horowitz, A. Brand, J. Van Steveninck, T. M. A. R. Dubbelman, Transfus. Med. Rev. 1996, 10, 15.

[30] A. J. T. Naik, S. Ismail, C. Kay, M. Wilson, I. P. Parkin, Mater. Chem. Physi. 2011, 129, 446.

[31] C. Piccirillo, S. Perni, J. Gil-Thomas, P. Prokopovich, M. Wilson, J. Pratten, I. P. Parkin, J. Mater. Chem. 2009, 19, 6167.

[32] N. Komerik, M. Wilson, J. Appl. Microbiol. 2002, 92, 618.

[33] R. C. Souza, J. C. Junqueira, R. D. Rossoni, C. A. Pereira, E. Munin, A. O. Jorge, Lasers med. Sci. 2010, 25,385 .

[34] S. Noimark, C. W. Dunnill, C. W. M. Kay, S. Perni, P. Prokopovich, S. Ismail, M. Wilson, I. P. Parkin, J. Mater. Chem. 2012, 22, 15388.

[35] S. Perni, C. Piccirillo, J. Pratten, P. Prokopovich, W. Chrzanowski, I. P. Parkin, M. Wilson, Biomaterials 2009, 30, 89 .

[36] E. Ozkan, E. Allan, I. P. Parkin, $R S C A d v .2014,4,51711$.

[37] S. Noimark, M. Bovis, A. J. MacRobert, A. Correia, E. Allan, M. Wilson, I. P. Parkin, RSC Adv. 2013, 3, 18383.

[38] S. Noimark, E. Allan, I. P. Parkin, Chem. Sci. 2014, 5, 2216.

[39] A. J. Coury, P. C. Slalkeu, P. T. Cahalan. K. B. Stoke, C. M. Hobot, J. Biomater. Appl. 1988, 3, 130

[40] T. Nyström, Arch. Microbiol. 2001, 176, 159.

[41] C. W. Boylen, M. H. Mulks, J. Gen. Microbiol. 1978, 105, 323.

[42] S. Shrivastava, T. Bera, A. Roy, G. Singh, P. Ramachandrarao, D. Dash, Nanotechnology 2007, 18, 225103.

[43] W. K. Jung, H. C. Koo, K. W. Kim, S. Shin, S. H. Kim, Y. H. Park, Appl. Environ. Microbiol. 2008, 74, 2171.

[44] W. R. Li, X. B. Xie, Q. S. Shi, H.Y. Zeng, Y. S. OU-Yang, Y. B. Chen, Appl. Microbiol. Biotechnol. 2010, 85, 1115 .

[45] Y. Cui, Y. Zhao, Y. Tian, W. Zhang, X. Lu, X. Jiang, Biomaterials 2012, 33, 2327.

[46] J. F. Hernandez-Sierra, F. Ruiz, D. C. Pena, F. Martinez-Gutierrez, A. E. Martinez, J. Guillen Ade, H. TapiaPerez, G. M. Castanon, Nanomed. Nanotech. Biol. Med. 2008, 4, 237.

[47] R. Roots, S. Okada, Radiat. Res. 1975, 64, 306.

[48] R. W. Redmond, I. E. Kochevar, Photochem. Photobiol. Sci. 2006, 82, 1178.

[49] C. W. Dunnill, K. Page, Z. A. Aiken, S. Noimark, G. Hyett, A. Kafizas, J. Pratten, M Wilson, I. P. Parkina, J. Photochem. Photobiol. A 2011, 220, 113

[50] S. Noimark, J. Weiner, N. Noor, E, Allan, C. K. Williams, M. S. P. Shaffer, I. P. Parkin, Adv. Funct. Mater. 2015, 25, 1367.

[51] J. M. Allen, C. J. Gossett, K. Sandra, S. K. Allen, J. Photochem. Photobio. B 1996, $32,33$. 
[52] C. Gerber, H. P. Lang, Nat. Nanotech. 2006, 1, 3

[53] Woodrow Wilson International Center for Scholars. A nanotechnology consumer products inventory, www.nanotechproject.org/consumerproducts2007, accessed: 2007.

[54] N. Vigneshwaran, A. A. Kathe, P. V. Varadarajan, R. P. Nachane, R. J. Balasubramanya, J. Nanosci. Nanotechnol. 2007, 7, 1893.

[55] T. M. Tolaymat, A. M. El-Badawy, A. Genaidy, K. G. Scheckel, T. P. Luxton, M. Suidan, Sci. Total Environ. 2010, 408, 999.

[56] S. M. Moghimi, A. C. Hunter, J. C. Murray, Pharmacol. Rev. 2001, 53, 283.

[57] J. Panyam, V. Labhasetwar, Adv Drug Delivery Rev. 2003, 55, 329.

[58] M. Ahamed, M. S. Alsalhi, M. K. J. Siddiqui, Clin. Chim. Acta. 2010, 411, 1841.

[59] J. H. Ji, J. H. Jing, J. U. Yoon, J. D. Park, B. S. Choi, Inhal. Toxicol. 2007, 19, 857.

[60] J. S. Hyun, B. S. Lee, H. Y. Ryu, J. H. Sung, K. H. Chung, I. J. Yu, Toxicol. Lett. 2008, 182, 24.

[61] H. Y. Lee, Y. J. Choi, E. J. Jung, H. Q. Yin, J. T. Kwon, J. E. Kim, J. Nanopart. Res. 2009, 12, 1567.

[62] Y. S. Kim, J. S. Kim, H. S. Cho, D. S. Rha, J. M. Kim, J. D. Park, B. S. Choi, R. Lim, H. K. Chang, Y. H. Chung, I. H. Kwon, J. Jeong, B. S. Han, I. J. Yu, Inhal. Toxicol. 2008, 20, 575.

[63] National Occupational Health and Safety Commission. Approved Criteria for Classifying Hazardous Substances.

http://www.safeworkaustralia.gov.au/sites/SWA/about/Publications/Documents/258/ApprovedCriteria_Cl assifying_Hazardous_Substances_NOHSC1008-2004_PDF.pdf, accessed: Oct, 2004

[64] Carolina biological supply company, Safety Data Sheet: Toluidine Blue O, http://www.carolina.com/pdf/msds/TOLBLUEOGHS.pdf, accessed: April, 2013.

[65] American Mastertech, Material Safety Data Sheet in Accordance with ISO/DIS 11014: Toluidine Blue O, http://www.americanmastertech.com/PDF/SSSTTBO.PDF, accessed: July. 2013

[66] J. Lin, L. J. Bi, Z. G. Zhang, Y. M. Fu, T. T. Dong, Laser Med. Sci. 2010, 25, 233

[67] A.A.S Warnakulasuriya, N. W. Johnson' J. Oral Pathol. Med. 2006, 25, 97. 